\title{
Russian writers ' aphorisms as a reflection of Russian linguoculture and the basis for the formation of a harmoniously developed personality
}

\author{
Anzhelika Korolkova ${ }^{1}$, Tatyana Novikova $^{2}$, and Anastasia Razumnaya ${ }^{1, *}$ \\ ${ }^{1}$ Smolensk State University, , Przhevalskogo Str., 4, 214000 Smolensk, Russia \\ ${ }^{2}$ Smolensk State Agricultural Academy, Bolshaya Sovetskaya Str., 4, 214000 Smolensk, Russia
}

\begin{abstract}
The article deals with aphoristics as a translator of the basic concepts of Russian linguoculture. The history of Russian aphorism reflects the history of the ethnic group, as well as all the changes in the public consciousness, while simultaneously fixing and preserving the same basic values. The researchers conducted a semantic analysis of the corpus of aphorisms recorded in the Dictionary of Aphorisms of Russian Writers.
\end{abstract}

\section{Introduction}

Russian culture, Russian literature and linguistics have always been interested in the wise word and aphoristics. It is well known that the history of Russian Aphoristics began with the history of Old Russian literature. Let us remember, for example, the aphorisms in "Teaching Your Children" by Vladimir Monomakh or "Supplication" by Daniel Zatochnik.

However, many theoretical problems have remained unsolved so far, although aphoristics has been studied in various aspects. All existing points of view on the nature of aphorisms can be summarized and divided into four groups:

- an aphorism is a literary genre (N. T. Fedorenko, L. I. Sokolskaya, [1] S. A. Shatalova [2]; T. I. Damm [3] , etc.);

- an aphorism is a special form of presentation of philosophical views (I. V. Lukyanets and N. O. Guchinskaya [4;5]; L. S. Chumanov [6]; V. N. Nazarov [7], etc.);

- $\quad$ an aphorism - the linguistic phenomenon of a language (D. A. Kryachkov [8]; V. G. Kostomarov, E. M. Vereshchagin [9] S. G. Shulezhkova [10], Ivanov E. E. [11], etc.);

- an aphorism is a linguistic unit of phraseology (S. G. Gavrin [12], Lomakina O. V. [13], Mokienko V. M. [14], Alefirenko N. F. [15;16] Korolkova A.V. [17], etc.) The basis for understanding the essence of aphorisms and aphoristics, in our opinion, should be an awareness of the dual nature of this phenomenon: both as a genre of literature, and as a part of phraseology in a broad sense. Note that for the

\footnotetext{
* Corresponding author: razumnayapochta@gmail.com
} 
first time this point of view was expressed by Yu.E. Prokhorov in his $\mathrm{PhD}$ thesis "Linguistic and cultural description of Russian Aphoristics for educational purposes" (1977) [18].

Since an aphorism is a statement of a completely stable form, it has a direct relationship to phraseology in the broad sense. In a broad sense, phraseology includes not only the actual phraseological units according to the classification of Academician V. V. Vinogradov (from the point of view of stability/instability of the form - these are merges, combinations and unities), but also paroemias, comparative figures of speech, stable expressions of a nominative nature.

We believe that an aphorism is "in the most general sense, it is advisable to call an aphorism a short phrase of the phraseological type, which has such properties as the presence of concept words in the structure; categorization, reproducibility. An aphorism can have such optional features as subjectivity, originality, paradoxical feature, unexpected wording, the presence of a figurative meaning, the ability to express universal truths, etc."

The modern Russian language space embodies the concept sphere of the people, the "cultural meanings" of language signs. Stable word complexes, including aphorisms and winged expressions, are an integral part of the concept sphere and the cultural space of the language. Aphoristics not only expresses stereotypical ideas, but also translates the basic concepts of Russian linguoculture, and is the center of a conceptual picture of the world that is valuable for an ethnic group. The genesis of aphoristics in Russian linguoculture is associated with changes in the language system that reflects everything that happens in real life.

Thus, the history of Russian aphoristics reflects the history of the ethnic group, as well as all the changes in the public consciousness, while simultaneously fixing and preserving the same basic values. Russian aphoristics has recorded since ancient times such unchanging concepts as Motherland, love, friendship, justice, God, and Russian (native) language, man, time, truth, conscience, etc.

In the modern world, in the context of globalization and at the same time in the conditions of special attention to national and cultural roots, it is incredibly difficult for society to form a harmoniously developed personality, because there is a polarization of views, the emphasis of moral foundations is shifting. Russian aphoristics, while preserving the deep moral foundations, shows the development guidelines for a harmoniously developed personality.

\section{Materials and Methods}

Semantic analysis of the corpus of aphorisms recorded in the Dictionary of Aphorisms of Russian Writers [19]. When extracting aphorisms from the contexts of journalistic or literary texts, the method of identifying concepts (keywords) in the utterance was used to fix them in the dictionary; structural analysis of lexicographic works was also used.

\section{Results and Discussion}

Russian aphorisms, sayings of Russian writers, poets, scientists, and artists are recorded in a variety of lexicographic works. Russian dictionaries of aphoristics can be used in a very brief form to learn the wisdom of the previous centuries of the development of Russian linguoculture, the Russian ethnos.

At one time, Leo Tolstoy expressed a similar idea in a well-known aphorism: You often hear young people say: I don't want to live with someone else's mind, I'll think it over 
myself. Why do you need to think things through? Take what's ready and move on. This is the strength of humanity.

With the adage of Leo Tolstoy, you can not only agree, but also develop it, suggesting that you actively use the aphorisms recorded in dictionaries when teaching both schoolchildren and students.

At the same time, it should be noted that aphorisms not only simply record the wise thoughts of famous people, while at the same time reflecting in diachrony changes in the public consciousness of an ethnic group, but also make you think about these changes. Aphoristics shows the dynamics of the development of the concept sphere of the people, while maintaining almost unchanged basic values. So, here is an example of aphorisms from the "Teaching to your Children" by Vladimir Monomakh:

Turn away from evil, do good, find peace and drive away evil, and live forever and ever.

$<$ It is necessary $>$ not to turn away from teaching those who are fond of power, not to put the general honor in anything.

Above all, do not have pride in your heart and mind, but say: we are mortal, today we are alive, and tomorrow we are in the grave.

In numerous dictionaries of aphorisms, winged expressions, wise thoughts are recorded, which can become a reference point for personal development. The history of lexicography of Russian aphoristics goes back almost two centuries.

Note that the first collections of aphorisms in Russian appeared in Russia only in the XIX century. These are "Aphorisms, or Selected thoughts of various writers" (1816) by K. Smitten [20] and the collection "Historical Aphorisms" by M. P. Pogodin (1827, 1836) [21].

The great interest in aphorism is also evidenced by the fact that even the philosophers of the XIX century preferred to express their thoughts with the help of aphorisms. So, for example, did P. Ya. Chaadaev in the famous book "Thoughts and aphorisms". Note that not all the statements placed in this book can be attributed to the aphorisms that make up the core of this genre. However, P. Ya. Chaadaev wrote the book in French and clearly focused on similar collections of adages by La Rochefoucauld and Pascal, consisting mainly of maxims.

In the XIX century, the imagination of the brothers Zhemchuzhnikov and A. K. Tolstoy created the mythical author Kozma Prutkov, who, however, excellently wrote aphorisms. Of course, aphorisms of a completely different plan than its famous predecessors, comic aphorisms. "Fruits of Thought" by Kozma Prutkov is a great success with readers to this day. The answer to this lies both in the choice of topics for aphorisms, and in the elegant form of grammatical embodiment of humorous sayings.

At the beginning of the XX century, aphoristics was on the rise. Interest in it increased enormously already at the end of the XIX century. It is believed that in a period of changes, people try to find answers to their questions in the wisdom of previous generations. So it was at the turn of the XIX-XX centuries and at the turn of the XX and XXI centuries. However, the turn of the XIX-XX centuries in the history of aphoristics was distinguished by an abundance of books of separate aphorisms. Among them are: "Thoughts and Aphorisms" by D. S. Khristoforych (1897) [22]; "Thoughts and Aphorisms" by D. H. Tutaev (1898) [23]; "About Happiness" by N. A. Lukhmanova [24]; "Thoughts and Aphorisms" by I. O. Pirozhnikov (1901) [25]; "Thoughts, Aphorisms and Negatives" by M. V. Bezobrazova (1902) [26]; "Thoughts and Aphorisms" by A. G. Rubinstein (1903) [27], etc.

Of particular interest to both contemporaries and researchers of our day are the books of isolated aphorisms of Leo Tolstoy. He wrote several books like that. These are "Thoughts of wise people for every day" [28], and "Circle of reading" [29], and "For every day" [30], 
and "The Way of Life" [31]. These books can not be called a collection of aphorisms, since they contain, in addition to the aphorisms of various authors, the thoughts and sayings of Leo Tolstoy himself, who, following the traditions of ancient Russian literature, considered it possible to borrow the thoughts of other authors and rebuild them according to his views. Tolstoy himself, in the preface to the Circle of Reading, noted that it is possible and should be free to deal with quotations from other writers, and the classical reverence for each phrase "is a very important and harmful prejudice" [29, 470]. In the collection "The Way of Life" he put this position into practice and so changed many sayings that he even "found inconvenient to sign them with the names of their authors." [31, 17]. N. T. Fedorenko and L. I. Sokolskaya wrote in great detail about the aphoristic legacy of L. N. Tolstoy in the monograph "Aphoristics", they pointed out that those books could be called "an apology for love and kindness". In a sense, the analysis of L. N. Tolstoy's aphorisms given in this book turned out to be not entirely objective, since the authors of the monograph complained that it was difficult to understand " what thoughts <Leo Tolstoy has! - A. K.> are true, and which reflected the erroneous worldview of the writer" $[1,125]$. It is completely unclear by what criteria it is possible to determine the "falseness" of Leo Tolstoy's worldview. The creative heritage of Leo Tolstoy is huge and a complete edition of his aphorisms, including individual books and many introductory aphorisms, would make up several large volumes. Tolstoy's aphoristics is edifying, instructive, because he considered the correction of people's morals to be the main goal of literature. He considered himself responsible for everything that happened in Russia, and tried to correct the situation with the help of a pen. Russian language Many of Leo Tolstoy's aphorisms are dedicated to Russia, the Motherland, the Russian people, and the Russian language.

For example: The moral strength of the Russian people is great. Many political truths will come out and develop in the current difficult moments for Russia. The feeling of ardent love for the fatherland, which rose up and resulted from the misfortunes of Russia, will leave traces in it for a long time.

What a lovely folk speech! And picturesque, and touching, and serious.

Do not believe your own words or those of others, but believe your own deeds and those of others.

The aphorisms of Leo Tolstoy are extensive in scope, he has few aphorisms that represent a single sentence, more often in his artistic and journalistic texts you can find aphoristic statements. Leo Tolstoy was one of the first in the history of Russian aphoristics to express his attitude to this form of presentation of thoughts, he believed that "aphorisms are almost the best form for the presentation of philosophical judgments", they develop the power of the mind, they are direct and bold.

The lexicography of aphoristics of the XIX-early XX century is classical both in terms of the breadth of topics covered and in terms of the beginning of the development of individual trends. It was at the end of the XIX century that the first separate books of Russian swindlers, collections of aphorisms of foreign writers, appeared. Aphorism penetrates from the field of artistic thought into journalism, into scientific works, and actively invades everyday speech from the pages of newspapers, magazines, and books.

The October Revolution of 1917 marked the beginning of a new era in the history of the Russian state, culture and art. All revolutionary upheavals required verbal support and it was found in aphorisms from the works of Rousseau, Diderot, Montesquieu, Marx, Engels, and then Lenin and Stalin. In the period following the October Revolution, no political meeting or demonstration was complete without aphoristic statements. It was during this period that the statements of the country's leaders began to acquire an aphoristic character due to mass quoting and turn into winged expressions. This trend was preserved in the collections of Russian aphoristics until the end of the XX century. 
In the 30 s of the XX century, aphoristics reflected all the changes that took place in the country. The classic aphorisms were the statements of Stalin, they were known and quoted by everyone. Let us quote one of them: "The son is not responsible for the father."

During the Great Patriotic War, patriotic aphoristics is actively developing, which reflects the themes of the motherland, heroism, life and death in the name of freedom, etc. Many phrases printed on posters and leaflets become winged, the same processes occur with individual phrases from the verses of popular songs. Many statements from popular songs become winged. During this period of time, a collection of aphorisms of famous authors, united by one theme of the native land, the fatherland, is published. The book of sayings, compiled by A. D. Deev, was called "Rodina" (the first edition in 1942, the second -1943, the third-1944) [32].

In the $50 \mathrm{~s}$, books of aphorisms are not published. The destruction did not contribute to the interest in the sharp and accurate word, in addition, the aphoristic sayings of many famous poets, writers, publicists, and politicians remained either forbidden or generally unknown to the general reader.

The 60-70-80 years retained the previous trend of little interest in the development of domestic aphoristics, although at this time books of aphorisms, wise thoughts, quotations from the works of ancient authors, medieval thinkers, and encyclopedists appeared. Such are, for example, the collections "Golden Placers" by I. B. Tumarkin (1959) [33]; "In the World of Wise Thoughts" by S. Karin (1962) [34]; "Thoughts and Aphorisms" by P. Landesman and Y. Soghomonov (1962) [35]; "Aphorisms" by E. Reise (1964) [36]; "Wise Word" by A. Sobolev (1966) [37]; "Aphorisms on Foreign Sources" by J. Berlin (1966) [38]; "Aphorisms" by S. Ignatiev (1972) [39]; "The Word about the Book" by E. Lichtenstein (1969) [40]; "The Word about Science" by E. Lichtenstein (1976) [41]; "The Cup of Wisdom" by V. Vorontsov (1978) [42], also in the dictionaries "Aphorisms: According to Foreign Sources" [43] (1985; compiled by P. P. Petrov and Ya. V. Berdin) and "Ancient Aphorisms" [44] (1987; compiled by Kazachenok T. G., Gromyko I. N.).

E. S. Lichtenstein in the book" The Word about Science "[41] proposed a thematic principle of the arrangement of the material and divided it into chapters: "Science in the centuries", "Science and modernity", "Humanism of science", "Laboratory of the scientist", "Science and Knowledge" and "Kunstkamera". He provided each chapter with a preface, and the book as a whole with an alphabetical index of the names of the authors of the aphorisms. The compiler of the collection, of course, had to pay tribute to the political system of Soviet reality, but in percentage terms, the statements of the classics of MarxismLeninism are insignificant.

The already mentioned book "The Cup of Wisdom" is also indicative. The author of the collection of aphorisms was V. V. Vorontsov. Although the collection does not contain a preface with theoretical reflections, it is nevertheless very valuable. In this book, the principle of thematic distribution of the material is also proposed, and the first thematic section offers the reader a section - "on aphorisms". All the aphorisms in the section "about aphorisms" in one way or another express one idea - it is necessary to know the history of mankind, set out in aphorisms, to reflect on the wise thoughts of aphorisms, to learn and comprehend the truth together with them.

At the turn of the XX - XXI centuries, the interest in aphoristics increased many times. More and more collections of aphorisms, sayings, and catch phrases were published. However, quantity has never yet denoted quality. Therefore, many publications bring even more chaos to the questions about the theory of aphorisms, in the principles of their lexicography. Such "garbage" publications discredit aphoristics, having nothing in common with the classical aphoristic fund of Russian linguoculture. 
In contrast to low-quality lexicographic publications, dictionaries of aphorisms with a serious scientific description are created, which help modern people to preserve moral guidelines.

"Russian Writers' Dictionary of Aphorisms" created in 2004 and reissued in 2005 and 2007, "the Dictionary of Aphorisms of Russian Writers of the XVII - XX Centuries" [19] was created by a team of authors and had an original concept.

At the beginning of the work, the authors of the dictionary had to solve a problem of a terminological nature, the question of the linguistic essence of the aphorism, then the concept of the "Dictionary of Aphorisms of Russian Writers" was compiled.

Firstly, the principle of the thematic arrangement of aphoristic material, which is widely used in modern editions of aphorisms, is rejected. Note that the principle is quite productive, but discredited in many popular dictionaries.

It was supposed to give a kind of anthology of aphorisms of most writers and poets of Russian literature, starting from the XVIII and ending with the XX century. The dictionary includes material extracted from the works of Russian writers, let us specify Russianspeaking writers, since the dictionary includes statements by Fazil Iskander, Vasil Bykov, Chingiz Aitmatov, Vladimir Nabokov, and Yanka Kupala. We believe that we have no right to exclude these remarkable writers from our field of view, from the history of Russian literature.

For example: Wisdom is a mind infused with conscience (F. Iskander)

Secondly, we tried to cover an extremely extensive material, considering the texts of writers starting from the XVIII century, from A. Kantemir, V. Kapnist, A. Sumarokov, finishing with the most modern works that were published a year or two ago. Among the modern writers whose aphorisms are included in the dictionary, we can name Yu. Polyakov, V. Pelevin, etc. We have not seen such a wide coverage of the material in the latest dictionaries on aphoristics.

For example: There is, apparently, some strange correspondence between the general pattern of life and those small stories that constantly happen to a person and to which he does not pay attention. (V. Pelevin)

Of course, the completeness of extracting aphorisms from texts will not always be absolute. It is impossible to say that all the aphorisms of A. S. Pushkin, L. N. Tolstoy or A. M. Gorky will be presented. This task is almost impossible.

Thirdly, Russian literature is an integral and indivisible whole, so the dictionary presents the aphorisms of writers and poets of all three waves of the tragic Russian emigration.

Fourthly, we tried to avoid numerous repetitions of aphorisms found in many dictionaries, "wandering" from one edition to another, and used materials not presented in such books.

Fifthly, we have presented in our dictionary the aphorisms of writers and poets of both the "first row" and the "second row". We believe that it would be wrong to take into account the works of only famous authors, even if they are the glory of Russian literature. Writers and poets of the "second and third rows" also defined the history of Russian literature and influenced the development of the literary language and the formation of moral values.

Sixthly, we believe that for the specific material of our dictionary, the following structure of the dictionary entry turned out to be the most productive:

- full name of the author, and the pseudonym and real surname, years of life are indicated. In some cases, the author's name needs an accentological explanation, in which case the emphasis is placed;

- then a number of aphorisms in alphabetical order. 
The dictionary is equipped with an index of key words-concepts that relate the utterance to thematic blocks, which makes it easier to find an aphorism of a certain topic. The bibliography lists all the texts from which the aphorisms were extracted.

This dictionary became the basis for further lexicographic work. Modern conditions for the development of educational space require interactive resources. Therefore, it was decided to include the "Dictionary of aphorisms of Russian writers" in the structure of the lexicographic site "Map of Words". Russian dictionary is supposed to become the basis for the study of Russian aphoristics and, accordingly, the basic values of Russian linguoculture. Each utterance will be available to users with appropriate comments about who it belongs to, from which work of Russian literature it is extracted. Keywords-concepts from the interactive dictionary of aphorisms of Russian writers will be correlated with the corresponding lexemes from the explanatory dictionary, i.e. active cross-references are provided, which greatly facilitates working with the dictionary.

In general, it should be noted that the lexicographic popularization of Russian aphoristics in the Russian and foreign educational space makes it possible to focus the attention of modern people (not necessarily only young people) on the basic values of the ethnic group.

\section{Conclusion}

In today's post-industrial society, the problem of forming a harmoniously developed personality is incredibly relevant and represents a serious problem. Young people-school graduates and even students of universities and colleges, who receive a large amount of theoretical and practical knowledge, are not able to realize their responsibility not only for their future, but also to approach the issues of citizenship responsibly, to think about the future of their country. This, unfortunately, is a global trend, young people are infantile. Unfortunately, in the Russian Federation, there are also global trends when the sociocultural maturation of young people is delayed. Infantilism appears in cases when a young person has no authority, neither in the family nor in the social environment, there is a real spiritual and moral crisis of the individual. At the same time, young people do not have a basic system of values that helps self-determination.

The process of infantilization can be resisted only if the goal in the educational space is the formation of a harmoniously developed personality. Let us clarify that a harmoniously developed person should be considered a person who has creative potential, is able to transform the socio-cultural space around him and in the whole society, and also combines physical perfection and spiritual wealth.

The formation of a harmoniously developed personality is associated with humanitarian education, with the development of the inner world of a person, which in turn is associated with the spiritual culture of society. The spiritual and moral culture of the society is connected with the basic values of the ethnic group, which are recorded in aphoristics. Therefore, the study of aphoristics in the educational process is an urgent need.

The most productive way to study aphoristics is to refer to scientific lexicographic works, dictionaries of aphorisms and catch expressions of Russian classics. Russian classical writers ' thematic dominants completely coincide with the constants of Russian culture, recorded in the dictionary of Yu. S. Stepanov. Based on the sayings of A. S. Pushkin, F. M. Dostoevsky, L. N. Tolstoy, A. P. Chekhov, and I. S. Turgenev recorded in dictionaries, one can consider the value paradigm of the Russian world, including such conceptual antinomic concepts as life/death, faith/lack of faith, war/peace, wisdom/mind/stupidity, truth/lie, grief/joy, loyalty/betrayal, etc. A special axiological system of values in Russian linguoculture (and this is recorded in aphoristics) is Russia, Motherland, love, friendship, people, native language, art. In the Russian aphoristics of the 
XX century, among the sayings of writers, poets, and cultural figures, aphorisms that are thematically related to the understanding of the tragic history of Russia, the revolution, the Civil War, and the Great Patriotic War, which form a single semantic space - the "tragic perception of reality", occupy a large place. Russian aphoristics does not just fix the basic values, but represents them in diachrony, demonstrating the changes in the value system of a person in the Russian world.

By studying aphorism, each person is enriched spiritually, becomes familiar with the deep foundations of the axiological values of the ethnic group. Russian writers' aphorisms, being a reflection of the Russian linguistic culture in diachrony, can be the basis for the formation of a harmoniously developed personality.

\section{References}

1. N. T. Fedorenko, L. I. Sokolskaya, Aphoristics (1990)

2. S. A. Shatalova, Linguistic bases of aphoristics in F. M. Dostoevsky's literary texts (based on the material of the novels "Demons" and "Teenager") (2000)

3. T. I. Damm, Small-format speech genres of the modern Russian newspaper (2003)

4. I. V. Lukyanets, Analysis of styles of foreign fiction and scientific literature, 7 (1996)

5. N. O. Guchinskaya, Intertextual connections in a literary text. St. Petersburg (1993)

6. L. S. Chumanov, Materials of the XII International conference-exhibition "Information Technologies in Education" (2002)

7. V. N. Nazarov, Ethics: dictionary of aphorisms and sayings (1995)

8. D. A. Kryachkov, Linguistic aphorism as a means of representing the speaker in the American political discourse: On the material of the election campaign (2002)

9. V. G. Kostomarov, E. M. Vereshchagin, Russian proverbs, sayings, winged expressions: A linguacultural dictionary (1980)

10. S. G. Shulezhkova, Winged expressions of the Russian language, their sources and development (2002)

11. E. E. Ivanov, Bulletin of the Peoples ' Friendship University of Russia. Series: Theory of language. Semiotics. Semantics, 11(4) (2020)

12. S. G. Gavrin, Scientific notes of the Perm Pedagogical Institute, 87 (1971)

13. O. V. Lomakina. Implementation of the functional potential of winged expressions in modern Russian journalism, 1(55) (2019)

14. V. M. Mokienko, Medialinguistics, 3(13) (2016)

15. N. F. Alefirenko, Phraseology and worldview of the people. Materials of the International Scientific Conference in 2 parts. Phraseological picture of the world, 1 (2002)

16. N. F. Alefirenko, I. I. Chumak-Zhun, A. Petrikova, Rusin's picture of the world in the artistic discourse of Vasil Perova, 58 (2019)

17. A.V. Korolkova, RUDN Journal of Language Studies, Semiotics and Semantics, 11(3) (2020)

18. Yu. E. Prokhorov, Synopsis of a thesis of Candidate of Philology: (10.02.01) (1977)

19. A.V. Korolkova, A. G. Lomov, A. N. Tikhonov, Dictionary of aphorisms of Russian writers (2007)

20. K. Smitten, Aphorisms (1816)

21. M. P. Pogodin, Historical aphorisms $(1827,1836)$ 
22. D. S. Khristoforych, Thoughts and aphorisms (1897)

23. D. H. Tutaev, Thoughts and aphorisms (1898)

24. N. A. Lukhmanova, About happiness (1898)

25. I. O. Pirozhnikov, Thoughts and aphorisms (1901)

26. M. V. Bezobrazova, Thoughts, aphorisms and negatives (1902)

27. A. G. Rubinstein, Thoughts and aphorisms (1903)

28. L. N. Tolstoy, Thoughts of wise people for every day, 41 (1957)

29. L. N. Tolstoy, Circle of reading, 42 (1957)

30. L. N. Tolstoy, For every day, 43-44 $(1929,1932)$

31. L. N. Tolstoy, The way of life, 45 (1956)

32. A.D Deev, Motherland (1942, 1943, 1944)

33. I. B. Tumarkin, Golden placers, (Thoughts and aphorisms) (1959)

34. S. H. Karin, In the world of wise thoughts (1962)

35. P. Landesman, Yu. Soghomonov, Thoughts and aphorisms (1962)

36. E. S. Reise, Aphorisms (1964)

37. A. I. Sobolev, Smart word (1966)

38. Ya. Berlin, P. Gribachev, Aphorisms on foreign sources (1966)

39. S. Ignatiev, Aphorisms (1972)

40. E. S. Lichtenstein, A word about the book (1969)

41. E. S. Lichtenstein, A word about science (1976)

42. V. Vorontsov, The Cup of Wisdom (1978)

43. P. P. Petrov, Ya. V. Berlin, Aphorisms: According to foreign sources (1985)

44. T. G. Kazachenok, I. N. Gromyko, Antique aphorisms (1987) 